\title{
Энергетическая система человека как часть природного энергообмена: значение для фундаментальной науки и медицины (часть I)
}

Статья продолжает цикл публикаций касательно вопроса организации энергетической системы человека. Впервые приведен междисциплинарный обзор, цель которого - показать взаимосвязь и общность фундаментальных энергетических процессов в природе и организме человека. Это имеет существенное значение для понимания сущности метаболизма в организме человека с позиций системной медицины и предлагаемой авторами новой магнитоэлектрохимической концепции обмена веществ.

Ключевые слова: энергетическая система, электромагнитное поле, метаболизм.

В познании организации и функционирования материального мира современная наука достигла возможности изучать фундаментальные основы межмолекулярныхпроцессов в системах - электромагнитные феномены. Для медицины данный научный аспект чрезвычайно актуален, поскольку эти знания могут открыть понимание сути явлений жизни, здоровья и в рамках новой магнитоэлектрохимической парадигмы обмена веществ способствовать углублению знаний как патогенеза заболеваний, так и дальнейшему усовершенствованиюподходов клечению ипрофилактике. Правотауже сделанных открытий и торжество единства естественных наук отображаютсяв целостностиполученныхнаучныхзнаний и взаимном ихмеждисциплинарном дополнении, позволяющем выстроить единую логическую концепцию природной энергетической системы. Благодаря научному прогрессу сегодня имеется возможность рассматривать энергетическую систему человека как часть природного энергообмена и находить общность, универсальность электромагнитных феноменов, составляющих основу организации жизни на Земле.

Фотон - фундаментальная частица электромагнитного поля (ЭМП) - рассматривается современной наукой как универсальный квант энергетических процессов в живой системе, в том числе организме человека. При этом все биологические системы, в том числе человек, в аспекте обмена энергии являются звеньями единой энергетической/магнитоэлектрохимической космически-планетарной цепи, в которой космическое излучение в сочетании сгеомагнитными факторами создает основудля существования и энергообмена/ метаболизма в живых системах планеты Земля. Космическое излучение предопределяет биологическую жизнь на Земле, поскольку: 1) является жизнеобеспечивающим источником фотонов и началом цепи природного энергообмена; 2) участвует в формировании магнитосферных показателей Земли. Наиболее изученным и энергетически определяющим для Земли есть так называемый ближний космос и прежде всего - Солнце. Энергия излучения Солнца образуется в термоядерной реакции синтеза гелия из четырех протонов водорода. Зона ядерных реакций занимает 0,1 радиуса Солнца. Ядерные космические процессы имеют длину волны ( $\lambda$ ) $3 \cdot 10^{15} \mathrm{M}$ при частоте $10^{23}$ Гц. Мощность солнечного излучения составляет $3,8 \cdot 10^{26}$ Вт, из которого на Землю попадает $8,4 \cdot 10^{16}$ Вт. Спектр волнового излучения Солнца включает всю полосу частот от герцевого диапазона до жесткого рентгеновского и ү-излучения, но максимум излучаемой им энергии, попадающей на Землю, приходится на видимую часть спектра и инфракрасное излучение, проходящие через "Окно прозрачности» атмосферы (ясная погода) - 45\%. Эта часть излучения дает основу всех известных энергетических процессов в биомолекулах, начинаясь фотосинтезом в растительном царстве и продолжаясь в таком же волновом диапазоне в излучениях биомолекул млекопитающих, в том числе организма человека.

Итак, основная доля излучаемой Солнцем энергии - фотоны, составляющие видимый спектр волновой энергии. Для этой части солнечного света характерна очень высокая стабильность энергопоступления на Землю - 1368 Вт/ ${ }^{2}$ с колебаниями в 11-летнем цикле не более $0,2 \%$. В оптическое «окно прозрачности» атмосферы весь видимый спектр волн от фиолетового до красного проникает на поверхность Земли практически без поглощения, в отличие от коротковолновой (ультрафиолетовое, рентгеновское и ү-излучение) идлинноволновойчасти солнечного излучения, которые почти полностью поглощаются атмосферой Земли. Формирование магнитосферных показателей Земли зависит от «космической погоды", а по сути — от явлений конвекции водородной плазмы (заряженных протонов иэлектронов, что есть электрическийток), имеющихместо на расстоянии 0,3 радиуса от поверхности Солнца. Движение водородной плазмы создает ЭМП, играющее фундаментальную роль во всех процессах солнечной активности. Изменения ЭМП Солнца обусловливают цикличность солнечного излучения - такназываемые автоколебания. По данным наблюдений, период последних составляет 22 года. Общее глобальное ЭМП Солнца по аналогии с земным имеет «магнитный стержень» вдоль оси вращения. Средняя скорость движения масс излучения солнца -400 км/с. Явление движения и расширения вещества короны на расстоянии нескольких десятков солнечных радиусов от поверхности названо солнечным ветром. Солнечный ветер обдувает все планеты и заполняет всю межпланетную среду. Химически это - водород с примесью гелия в ионизированном плазменном состоянии, физически - двигающаяся сплошная разряженная среда с плотностью частиц 9 в $1 \mathrm{~cm}^{3}$ (в атмосфере Земли $-10^{19}$ в $\left.1 \mathrm{~cm}^{3}\right)$, в которой могутпроисходитьгазодинамические явления и распространяться звук. Солнечный ветер создает собственное ЭМП и достигает Земли через 4,5 земных суток. За это время Солнце поворачивается на $60^{\circ}$ и силовые линии ЭМП солнечного ветра изгибаются, не теряя связи со своим источником - ЭМП Солнца. Это обусловливает секторальную структуру межпланетного ЭМП: часть силовых линий его тянется к северному магнитному полю солнца, часть - к южному. Величина ЭМП солнечного ветра - 0,770 нТл (в среднем - 7 нТл). Плотность плазмы в солнечном ветре 0,1-140 частиц в $1 \mathrm{~cm}^{3}$, скорость - 150-1000 км/с. При мощной хромосферной вспышке параметры возрастают, достигая максимума значений и скоростей, близких к скорости света (300 000 км/с). Сильная хромосферная вспышка на Солнце направляет плазменное облако к Земле, что изменяет вариации спектра электромагнитного (волнового) солнечного излучения, вызывает магнитосферные возмущения/бури и колебания магнитосферных показателей среды обитания. Все это определяет космические экологические показатели на Земле, имеет принципиальное биологическое и медицинское значение, обусловливая явления гелиохронобиологической и метеозависимости. При магнитной буре объективно регистрируют множество быстрых изменений напряженности магнитного поля (стрелка компаса беспорядочно дрожит и колеблется), что также сопровождается «бурей» в инфразвуке - биологически активном неслышным 
для человека диапазоне акустического спектра. Инфразвук распространяется по целому полушарию Земли, воздействуя несколько часов. Привычный состав магнитного спектра также меняется за счет повышения в сотни раз низких и сверхнизких частот, отсутствующих в обычном спектре (Владимирский Б.М., Темурьянц Н.А., 2000; Галль Л.Н., 2009).

Огромныйэкспериментальный материалпоказывает, что результаты космическихвоздействий выявляют на всехуровнях биологической организации - от одноклеточных организмов до нейрофизиологическихпроцессов человеческого мозга. Космические процессы влияют даже на результаты лабораторныхсугубо химическихили физических экспериментов (Соколовский В.В., 2008; Панчелюга В.А., Шноль С.Э., 2009; Христич Т.Н., Горбачевский А.В., 2009). Биоритмология имеет значение для терапевтической практики, поскольку показано, что эффективность лечения зависит и от правильно выбранной фазы его начала (Бланк М.А., Рябых Т.П., 2000).

ЭМПкосмическогопроисхождения не имеетвозможностиполностью проникать на Землю благодаря наличию геомагнитосферы. Земля, согласно официально принятой научной геофизической модели, имеет стационарное магнитное поле, которое формируется в результате течения электрических токов в высокопроводящем внешнем слое жидкого земного ядра. Основная его количественная характеристика - напряженность, наибольшая - на магнитных полюсах $(0,65$ гаусс (Гc), наименьшая - намагнитном экваторе $(0,35$ Гс) Средняя напряженность геомагнитного поля (ГМП) 0,5 Гс существует 3 млрд лет. По данным палеонтологических исследований, за 80 млн лет имели место 188 инверсий со средним интервалом полярности около 400 тыс. лет. Сегодня отмечают снижениеГМП; его «обнуление» ожидается приблизительно через 2000 лет. Высшие позвоночные плохо переносят с биологической точки зрения инверсии ГМП. На границе магнитосферы ГМП переходит в межпланетарное магнитное поле, связанное с Солнцем и вращающееся вместе с ним (Александров В.В., 2006).

Часть энергии Солнца способна проникать через магнитосферу Земли. При этом верхняя часть атмосферы Земли выполняет защитную функцию. Содержащиеся в верхних слоях атмосферные газы азот и кислород - первые соприкасаются с энергией коротковолновойчастисолнечного излучения (ультрафиолет, рентген, $ү$-излучение) и в силу его действия у них «отрываются» электроны, наступает их ионизация - они формируют так называемую ионосферу - часть атмосферы на высоте 50-250 км над поверхностью Земли. Высокая концентрация свободных электронов ионосферы создает на этих высотах высокопроводящий электрический слой, образующий внутреннюю сферическую полость, защищенную от низкочастотного излучения космического происхождения. Эта полость ведет себя как резонатор с основным тоном 8 Гц и в ней локализовано импульсное радиоизлучениеэлектрических разрядов молний. Наблюдениеза изменениями в ионосфере позволяет определять наступление и развитие магнитной бури, достигающей Земли через 2 сут первых коротковолновыхизлученийхромосфернойвспышки Солнца, попавших на Землю за 8 мин. В 20 км над поверхностью Земли атмосфера становится насыщенной кислородом, который забирает на себя энергию остального коротковолнового излучения Солнца и ионизируется, образуя озоновый слой из О. Озоновый слой практически полностью поглощает коротковолновое излучение с длиной волны до 260 нм. Это биологически важно, поскольку излучение с длиной волны 260 нм уже активно поглощается биомолекулами, вызывая их конформации, химические модификации, распад.

Таким образом, на поверхности Земли формируется результативное ЭМП - векторная сумма полей магнитосферы, ионосферы, ГМПи томуподобного, различающихся между собой спектральными и амплитудными характеристиками и переменной компонентой. Имеют значение идругие физическиеполя. Так, гравитационноеполе Земли - результат фундаментальных представлений науки, постулирующих, что это сила тяжести - физическое поле, от которого нельзя экранироваться, которое также определяет условия развития биоты на Земле. Гравитационная часть силы тяжести наповерхности Земли непостоянна и зависит от распределения масс в земной коре. При формировании различных по плотности участков пород между ними могут возникать гравитационные ступени и аномалии, гдеперепад ускорения силы тяжести может достигать 1\%. Над местами глубинных разломов земной коры (ширина - 10-15 км, длина - сотни километров) могут возникать геопатогенные зоны, над которыми ватмосферуподнимаютсяпотокиионизирующего излучения, газовые потоки, возникают электромагнитные эффекты, инфразвуковые явления. Деформации Земли порождают в земной коре акустические волны низких (инфра) частот, неслышного для человеческого уха диапазона акустического спектра, но имеющего значительную биологическую активностьивлияющего на эмоциональное ипсихическое состояние человека (метеозависимость и инфразвук). Сила земного притяжения зависит от космическихвлияний, определяющихпонятие «гравитационной неустойчивости». Наиболее изучены зависимости от Солнца и Луны (морские приливы, деформация твердого тела Земли и т.п.). Так, Луна максимально изменяет гравитационное поле пространства, над которым находится в новолуние, и минимально в полнолуние. Все это создает еще один дополнительный космический ритм, задающий еще одни ритмы живым организмам. Все изменения природного результативного ЭМП, несмотря на малые их величины, имеют значимые эффекты на биологическом уровне (Агаджанян Н.А., Макарова И.И., 2005; Галль Л.Н., 2009; 2010).

Солнечное излучение видимого спектра играет главную роль в обеспечении энергией кругооборота электронов в биосфере. На Земле фотоны включаются во второе энергетическое звено природного биометаболизма - фотосинтез-преобразование с аккумуляцией в органических веществах растительного мира. Зелеными растениями поглощается $0,02 \%$ солнечной энергии, достигшей Земли $\left(4 \cdot 10^{13} \mathrm{BT}\right)$, что обеспечивает фотосинтез, а через него - всю энергетику Земли. Половина солнечной энергии, усвоенной биологическими объектами, используется микроорганизмами. На долю человечества приходится 0,5\% энергии Солнца, потребляемой биосферой. Транспорт возбужденных п-электронов, обеспечивающий конвертирование солнечной энергии в макроэргическихсвязяхАТФ, свойственен не только зеленым растениям, но и хлорофиллсодержащим бактериям. На сегодня физико-химические процессы фотосинтеза фундаментально изучены и формализированы. Изучены цикличность свойств, светозависимость хлорофилла, скорость фотосинтеза за единицувремени и от интенсивности поглощенного света. Источником всего атмосферного кислорода служит вода, участвующая в реакциях фотосинтеза. При восстановлении углекислого газа до углевода осуществляется перенос 4 атомов водорода $\mathrm{H}_{2} \mathrm{O}$ на $\mathrm{CO}_{2}$. Изменение свободной энергии в реакциях фотосинтеза при преобразовании 1 молекулы О составляет около 500 кДж· моль ${ }^{-1}$, при этом затрачивается 8 квантов света с суммарной энергией примерно 1470 кДж · моль ${ }^{-1}$. Коэффициент использования солнечной энергии при фотосинтезе - 34\%. Эта свободная энергия поступает из фотохимических процессов, в которых участвует хлорофилл. Каждая молекула хлорофилла тесно связана с донором и акцептором электронов компонентов клеточной мембраны, фиксированных в ее определенных точках. Вне биомембраны фотосинтез не осуществляется. Также изучены аспекты переноса энергии в зависимости от вида хлорофилла (a, b), роль светособирающей пигментной матрицы, позволяющей задействовать в фотосинтезе всю видимую область электромагнитного спектра. Причем перенос энергии от различных пигментов этой матрицы нахлорофилл осуществляется по резонансному принципу. Фотосинтез осуществляется за счет перехода возбужденныхэлектронов с изменением ихспина. В ходе единственной многоступенчатой световой реакции двухтактного фотоэлектронного преобразования возникают молекулярный кислород, НАДФН (восстановленный НАДФ), а также АТФ. Дальнейшие аутотрофные биосинтетические реакции происходят в зеленых растениях за счет энергии, заключенной в электронах, принадлежащих НАДФН и АТФ. Лучше других реакций фотосинтеза изучен процесс образования 6-углеродной молекулы глюкозы из 6 молекул $\mathrm{CO}_{2}$ и 6 молекул $\mathrm{H}_{2} \mathrm{O}$ (реакция фиксации углекислого газа). 12 пар возбужденныхэлектронов, необходимых для осуществления этой реакции, поступают от НАДФН. Дополнительным поставщиком свободной энергии служат 18 молекул АТФ. Вклад НАДФН и АТФ в фотосинтез 1 моля глюкозы составляет 660 и 252 ккал соответственно. Аналогично углеводам происходит фотосинтез всех биологически важных макромолекул. Важно, что для синтезауглеводов, белков, жиров, нуклеиновыхкислот идругихвысокомолекулярных органических соединений из $\mathrm{CO}_{2}, \mathrm{H}_{2} \mathrm{O}$, нитратов, сульфатов и прочих относительно простых веществ необходим колоссальный приток электронов к ним. Установлено, что благодаря поглощению фотонов видимого диапазона солнечного спектра электроны достигают наивысшего биопотенциала в фотосистемах растений (Самойлов В.О., 2013). 
Энергетический метаболизм животного царства составляет третье звено энергетической природной цепи. Углеводы, белки, жиры служат основными питательными веществами для гетеротрофов. В клеточном дыхании/биологическом окислении ключевую роль играют потоки электронов и протонов, перемещающиеся по ферментному конвейеру - дыхательной цепи. Смысл функционирования дыхательной цепи - в получении энергии клетками и тканями из питательных веществ в процессе их окисления до $\mathrm{CO}_{2}$ и $\mathrm{H}_{2} \mathrm{O}$, неспособных кдальнейшему освобождению энергии посредством обычных химических реакций. Свободная энергия воды считается наименьшей в сравнении с другими биологическими молекулами потому, что заключена в $\sigma$-связях и не может химически прореагировать при температуре тела и других физико-химических параметрах организма животных и человека. Клеточное дыхание обеспечивает энергоснабжение всехпроцессов жизнедеятельности животныхичеловека. Процессы клеточного дыхания глубоко изучены и формализированы. Фундаментально важно, что из сопоставления шкалы восстановительныхпотенциалов компонентов систем фотосинтеза и дыхательной цепи следует, что солнечная энергия, конвертированная п-электронами при фотосинтезе, затрачивается преимущественно на клеточное дыхание (синтез АТФ). На этапе фотосинтеза за счет поглощения двух фотонов обеими фотосистемами (II и I) п-электроны переносятся от Р680 до ферредоксина, увеличивая свою свободную энергию примерно на 241 кДж $\cdot$ моль $^{-1}$. Ее небольшая часть расходуется при переносе п-электронов в зеленых растениях с ферредоксина на НАД $\Phi^{+}$. В результате синтезируются вещества, которые затем становятся пищей для гетеротрофов и превращаются в субстраты клеточного дыхания. В начале дыхательной цепи запас свободной энергии п-электронов составляет 220 кДж · моль ${ }^{-1}$. Значит, до этого энергия п-электронов, аккумулировавших солнечную энергию, снизилась всего на 21 кДж . моль ${ }^{-1}$. Это означает, что >90\% солнечной энергии, аккумулированной в зеленых растениях, доносится возбужденными п-электронами до дыхательной цепи митохондрий животных и человека. Таким образом, в ходе метаболизма энергия электронов с самого высокого энергетического уровня дискретно переходит на самый низкий в биосфере энергетический уровень - уровень воды. Энергетический обмен тела человека таков, что в нем за сутки в покое в ходе биологического окисления образуется около 300 мл эндогенной воды окисления. Объем ее образования определяется интенсивностью метаболизма, видом и массой окисленных субстратов клеточногодыхания: окисление 100 гжира образует примерно 100 мл воды, 100 г белка и 100 гуглеводов - 40 и 50 мл соответственно. Как итог в природе имеет место «энергетическое электронное колесо жизни»: электроны воды «оживляются» в процессе фотосинтеза, пополняя электронный фонд хлорофилла P680, по мере потери им своих п-электронов под действием Солнца, а клеточное дыхание вновь порождает воду, электроны которой не способны придать ей химическую активность в организме животных и человека.

При этом принципиальной особенностью цепи природного энергообмена в живых системах, в отличие от неживых, является свойство не только усвоения энергии, но и производство новой энергии более высокого уровня качества (Галль Л.Н., 2009; Самойлов В.О., 2013). Как отмечено в предыдущей публикации (Потяженко М.М., Невойт А.В., 2019), в живых клетках организма человека, как в условной вершине пищевой энергетической цепи, имеет место не только усвоение солнечной энергии, аккумулированной в пище растительного и животного происхождения, но и постоянная генерация и излучение ЭМП в ходе множественного биохимического метаболизма. На микроуровне это подтверждается тем, что живые клеточные структуры/ткани генерируют эндогенные когерентные ЭМП спектра частот в диапазоне 250-800 нм, а также излучения в инфракрасном и сверхчастотном диапазонах. На макроуровне наблюдается производство инфракрасного излучения (тепло), электрической и механической энергии (мышечные сокращения, движение), электромагнитной энергии (нервная и психическая деятельность, регуляторные процессы) и т.п. ЭМП и соответствующие частотные виды энергии обусловливают реализацию эндогенных колебательных ритмов (автоколебания, биоритмы, жизненные циклы) и всех процессов жизнедеятельности человека. Как указано выше, спектр излучения живых клеток полностью соответствует частотным характеристикам видимого спектра ЭМП излучения Солнца, попадающего на Землю. Совпадение амплитуд естествен- ных ЭМП и излучений клеток еще раз свидетельствует о единстве и универсальности фундаментальных аспектов природного энергообмена. На сегодня электромагнитная сущность, частотные характеристики тканей и органовчеловеческоготелапродолжают изучаться, представляя перспективное инвариантное направление современной медицины.

\section{Окончание - в следующей публикации.}

\section{Список использованной литературы}

Агаджанян Н.А., Макарова И.И. (2005) Магнитное поле Земли и организм человека. Экология человека, 9: 3-9.

Александров В.В. (2006) Экологическая роль электромагнетизма. СанктПетербургский гос. политех. ун-т, Санкт-Петербург, 716 с.

Бланк М.А., Рябых Т.П. (2000) Хронобиология и хрономедицина. Ф.И. Комаров, С.И. Рапопорт (ред.). Триада Х, Санкт-Петербург, с. 329-355.

Владимирский Б.М., Темурьянц Н.А. (2000) Влияние солнечной активности на биосферу - ноосферу. Гелиобиология от А.Л. Чижевского до наших дней. Изд-во Международ. независ. эколого-политологич. ун-та, Москва, 374 с.

Галль Л.Н. (2009) В мире сверхслабых. Нелинейная квантовая биоэнергетика: новый взгляд на природу жизни. Москва, 317 с.

Галль Л.Н. (2010) Биоэнергетика - магия жизни. Астрель, Санкт-Петербург, 349 c.

Панчелюга В.А., Шноль С.Э. (2009) Неоднородность пространства как фактор, определяющий результаты измерений. Санкт-Петербург, 400 c.

Потяженко М.М., Невойт А.В. (2019) Энергетическая система человека в свете современных физико-биологических знаний, концепций, гипотез. Укр. мед. часопис, 4(2) (132): 24-29.

Самойлов В.0. (2013) Медицинская биофизика. СпецЛит, СанктПетербург, 591 с.

Соколовский В.В. (2008) Тиолдисульфидная система в реакции организма на факторы окружающей среды. Наука, Санкт-Петербург, 121 с

Христич Т.Н., Горбачевский А.В. (2009) Электромагнитные поля, биоритмы и адаптация в организме человека. Біологія і фармація, 3: $67-71$.

\section{Енергетична система людини як частина природного енергообміну: значення для фундаментальної науки та медицини (частина I) \\ М.М. Потяженко, А.В. Невойт}

Резюме. Стаття продовжує цикл публікацій щодо питання організації енергетичної системи людини. Вперше наведено міждисциплінарний огляд, мета якого - показати взаємозв'язок іспільність перебігу фундаментальних енергетичних процесів у природі та організмі людини. Це має істотне значення для розуміння сутності перебігу метаболізму в організмі людини з позицій системної медицини іпропонованої авторами нової магнітоелектрохімічної концепції обміну речовин

Ключові слова: енергетична система, електромагнітне поле, метаболізм.

\section{Human energy system as a part of natural energy exchange: value for fundamental science and medicine (part l) \\ M.M. Potyazhenko, A.V. Nevoyt}

Summary. The article continues the cycle of publications about the organization of the human energy system. For the first time, an interdisciplinary review is presented to show the relationship and commonality of the flow of fundamental energy processes in nature and the human body. It is essential for understanding the essence of the course of metabolism in the human body from the standpoint of systemic medicine and proposed by the authors of new magnetoelectrochemical concept of metabolism.

Key words: energy system, electromagnetic field, metabolism.

\section{Адрес для переписки:}

Потяженко Максим Макарович

36011, Полтава, ул. Шевченко, 23

Украинская медицинская стоматологическая академия

кафедра внутренних болезней и медицины неотложных состояний

с кожными и венерическими болезнями

E-mail: umsainua@ukr.net

Получено 10.10.2019 